\title{
Pituitary Regulation of Preovulatory Estrogen Secretion in the Rat
}

\author{
TAKASHI HORI, MAKOTO IDE AND TAMOTSU MIYAKE \\ Shionogi Research Laboratory, Shionogi \& Co., Ltd., \\ Fukushima-ku, Osaka
}

\begin{abstract}
Synopsis
A role of pituitary on the ovarian estrogen secretion was investigated on the rats hypophysectomized at 1 p.m. in proestrus. The estrogen secretion was minimized within 3 hrs. after hypophysectomy. Rat pituitary extract (1 gland e.q.) intravenously injected $2 \mathrm{hrs}$. after hypophysectomy caused 11 fold increase of estrogen concentration in the ovarian venous blood within $1 \mathrm{hr}$, , the extent of which was comparable to that of intact control. Either LH or FSH alone was able to restore the estrogen secretion, and the time required to reach the maximal response was $1 \mathrm{hr}$. for $\mathrm{LH}$ and $2 \mathrm{hrs}$. for FSH. In the $1 \mathrm{hr}$. test, the minimal effective dose for NIH-LH-S 3 and NIH-FSH-S 1 appeared to be less than 0.25 and $2.5 \mu \mathrm{g}$ per rat, respectively. The total activities of the two preparations to produce estrogen appeared to be the same. Under the same conditions, $10 \mathrm{IU}$ of prolactin slightly stimulated the secretion, whereas $20 \mathrm{mU}$ of ACTH was quite negative. These results confirmed pituitary gonadotropin dependency of estrogen secretion from the ovary having ripened follicles. It was further demonstrated that the ovary, after completion of ovulatory surge of $\mathrm{LH}$, abolished its reactivity to the pituitary extract containing a sufficient amount of substance(s) in promoting estrogen secretion. An exogenous LH injected at 11 a.m. of proestrus also caused termination of ovarian estrogen secretion with a time lag of $3 \mathrm{hrs}$., the duration of which was equivalent to the interval between the initiation of ovulatory discharge of $\mathrm{LH}$ and termination of estrogen secretion in intact rats. Either NIH-FSH-S 4 or NIH-LH-S 12 was able to terminate estrogen secretion even at a minute dose as small as $10 \mu \mathrm{g}$ per rat. From these facts, it is considered that both FSH and LH provide a dual effect on ovarian estrogen secretion at the preovulatory stage, promotion and suppression; the former is an acute and direct action of hormones on steroidogenesis and the latter probably a delayed and indirect action of ovulation inducing hormone, the release of which initiates the differentiation of estrogen forming cells towards ovulation unfavorable to estrogen synthesis.
\end{abstract}

It has been firmly established that both follicle stimulating hormone (FSH) and luteinizing hormone $(\mathrm{LH})$ are indispensable for follicular growth and steroidogenesis in the ovary (Fevold, 1941; Greep et al., 1942; Lostroh and Johnson, 1966). Little has been known, however, about how estrogen secretion from the ovary having ripened follicles is controlled. It may be due to a lack of adequate methodology for distinguishing a very acute action of gonadotropin to promote estrogen secretion from a delayed effect of the hormone

Received for publication April 2, 1969. on cell growth and differentiation, which manifests itself by way of follicular growth, ovulation and luteinization.

Our previous work based on the direct measurement of estrogen concentration in the ovarian venous blood (Hori et al., 1968) elucidated the time schedule of ovarian secretion of estrogen during the rat estrous cycle, which had been assumed by the use of biological criteria such as uterine weight, uterine ballooning and vaginal cornification (Schwartz, 1964; Barnea et al., 1968), and also demonstrated hypophyseal dependency of ovarian estrogen secretion in the preovulatory rat as well as the acute 
promoting effect of gonadotropin, either $\mathrm{LH}$ or $\mathrm{FSH}$, on the estrogen secretion in the rat hypophysectomized at proestrus. Putting these results together with the data on a sequence of events occurring in preovulatory rats bred in our laboratory under the same lighting schedule (Miyake, 1968; Hori et al., 1968; Kobayashi et al., 1968; Uchida et al., 1969a), it is clear that a highly stimulated estrogen secretion at proestrus depletes rapidly and terminates in a few hours after the occurrence of LH release, which is accompanied with a prompt increase in progesterone secretion.

The present study was conducted to obtain further information on the factors stimulating estrogen secretion in preovulatory phase and an attempt was made to elucidate the mechanism of termination of estrogen secretion, in which ovulatory surge of $\mathrm{LH}$ or ovulating hormone possibly played an important role.

\section{Materials and Methods}

\section{Animals}

Female rats of the Wistar strain, weighing 170 to $250 \mathrm{~g}$, were maintained in an air-conditioned room $\left(25 \pm 1^{\circ} \mathrm{C}, 50-60 \%\right.$ humidity) illuminated $12 \mathrm{hrs}$. a day from 8 a.m. to 8 p.m. The rats exhibiting a regular 4-day estrous cycle were used after confirming at least 2 normal cycles by checking vaginal smears every morning.

\section{Preparation of pituitary extract}

The whole pituitary glands were isolated from a group of 10 to 15 rats each at 11 a.m. and 9 p.m. on proestrus, respectively The materials were then pooled and homogenized with a few $\mathrm{m} l$ of cold saline in a glass homogenizer kept in an ice bath. The homogenates were centrifuged at $0^{\circ} \mathrm{C}$ by $3020 \times \mathrm{g}$ for 30 mins. The supernatant was adjusted as one gland equivalent of the extract to be contained in a volume of $0.5 \mathrm{ml}$ saline per injection. The preparation was kept frozen until injection.

\section{Pituitar" hormone treatment}

In the experimet, ts designed to ascertain pituitary dependency of ovarian estrogen secretion, rats were hypophysectomized at 1 p.m. of proestrus by the trans-auricular method of Tanaka (1955) under sodium methyl-hexabital anesthesia $(25 \mathrm{mg}$ per rat, i.p.). Two hrs. after surgery, the rat pituitary extracts or pituitary hormones such as NIH-FSH-S 1 , NIH-LH$\mathrm{S}_{3}$, LTH (Prolactin, Teikoku-zoki) and ACTH (U.S.P. Corticotropin Reference Standard, 3rd), were injected into a tail vein at a volume of $0.5 \mathrm{ml}$ of saline solution. In order to test whether or not gonadotropin terminates a highly elevated estrogen secretion at proestrus, rats were injected intravenously with $\mathrm{NIH}-\mathrm{FSH}-\mathrm{S}_{1}$, NIH-FSH-S4, NIH-LH-S 3 or NIH-LH-S 12 at 11 a.m. in proestrus. Their estrogen secreting activities at 5 p.m. were compared with those of controls.

\section{Estrogen assay in ovarian venous blood plasma}

The samples of ovarian venous blood were collected individually for $30 \mathrm{mins}$. starting at specified time under pentobarbital sodium anesthesia $(10 \mathrm{mg}$ per rat, i.p.). The estrogenic activity of ovarian venous plasma was measured by the method described previously (Hori et al., 1968). The potency of plasma extract in terms of estradiol equivalent was usually calculated from a 3 -point assay using 5 and $100 \mathrm{pg}$ of estradiol as the standards, since the dose-response regressions on the ovarian venous plasma extracts were parallel with those of estradiol (Hori et al., 1968). A group of 8 ovariectomized mice were injected intravaginally with one-tenth of the final suspension containing $1 \mathrm{~m} l$ of plasma extract in a volume of $10 \mu l$ per mouse. Onetenth of the extract was taken into another tube and diluted to $100 \mu l$ with distilled water. This was used for the case where the value of original sample exceeded that of the standard estrogen. The identification of estrogen in the plasma extract was based on the fact that the stimulation of vaginal 2,3,5-triphenyltetrazolium chloride reduction was produced only by estradiol plus estrone fraction obtained after thin layer chromatography of the extract in the cyclohexane-ethylacetate $(3: 1)$ solvent system.

\section{Results}

\section{Estrogen secreting activity of pituitary hormones}

A highly elevated ovarian estrogen secretion in proestrus was minimized within $3 \mathrm{hrs}$. after hypophysectomy (Hori et al., 1968), indicating pituitary dependency of the estrogen secretion from the rat ovary having ripened follicles. An attempt was, therefore, made to clarify whether pituitary factors could restore a minimized estrogen secreting activity to the normal level. The results are presented in Table 1. Hypophysectomy at 1 p.m. followed by an intra- 
Table 1. Acute promoting effect of pituitary homogenate on ovarian estrogen secretion in rats hypophysectomized at proestrus

\begin{tabular}{lccc}
\hline \hline Treatment & $\begin{array}{c}\text { No. of } \\
\text { rats }\end{array}$ & \multicolumn{2}{c}{ Ovarian venous blood estrogen } \\
& 9 & $n g / m l$ plasma & ng/hr/ovary \\
\hline Saline & 7 & $0.30 \pm 0.13^{\mathrm{a})}$ & $2.1 \pm 1.10^{\mathrm{a})}$ \\
Pituitary extract $\mathrm{I}^{\mathrm{b})}$ & 9 & $3.48 \pm 0.70^{*}$ & $24.6 \pm 4.70^{*}$ \\
Pituitary extract $\left.\mathrm{II}^{\mathrm{c}}\right)$ & $1.82 \pm 0.40^{*}$ & $12.1 \pm 2.05^{*}$ \\
\hline
\end{tabular}

Rats were hypophysectomized at 1 p.m. in proestrus. The pituitary extract ( 1 gland equivalent per rat) were injected intravenously at 3 p.m. Ovarian venous blood was collected for 30 mins. starting at 4 p.m.

a) Mean \pm S.E., estradiol equivalent

b) Obtained from the proestrous rat at 11 a.m.

c) Obtained from the proestrous rat at 9 p.m.

* Statistically significant against hypophysectomized control group at $\mathrm{P}<0.05$.

Table 2. Acute promoting effect of pituitary hormones on ovarian estrogen secretion in rats hypophysectomized at proestrus

\begin{tabular}{|c|c|c|c|c|c|}
\hline \multirow{2}{*}{\multicolumn{3}{|c|}{ Treatment }} & \multirow{3}{*}{$\begin{array}{c}\begin{array}{c}\text { No. of } \\
\text { rats }\end{array} \\
9\end{array}$} & \multicolumn{2}{|c|}{ Ovarian venous blood estrogen } \\
\hline & & & & $\mathrm{ng} / \mathrm{m} l$ plasma & ng/hr/ovary \\
\hline Saline & & & & $0.30 \pm 0.13^{\mathrm{a})}$ & $2.1 \pm 1.10^{\mathrm{a})}$ \\
\hline \multirow[t]{4}{*}{ NIH-LH-S3 } & 0.2 & $\mu \mathrm{g}$ & 8 & $1.42 \pm 0.23 *$ & $7.3 \pm 0.83^{*}$ \\
\hline & 2.5 & $\mu \mathrm{g}$ & 9 & $2.08 \pm 0.40^{*}$ & $12.8 \pm 2.90 *$ \\
\hline & 25 & $\mu \mathrm{g}$ & 10 & $2.85 \pm 0.68 *$ & $13.1 \pm 3.49 *$ \\
\hline & 250 & $\mu \mathrm{g}$ & 9 & $3.23 \pm 0.93 *$ & $12.5 \pm 2.14 *$ \\
\hline \multirow[t]{3}{*}{ NIH-FSH-S1 } & 2.5 & $\mu \mathrm{g}$ & 7 & $0.86 \pm 0.14 *$ & $5.9 \pm 1.18 *$ \\
\hline & 25 & $\mu \mathrm{g}$ & 8 & $1.26 \pm 0.25 *$ & $8.1 \pm 1.43 *$ \\
\hline & 250 & $\mu \mathrm{g}$ & 8 & $1.13 \pm 0.23 *$ & $7.0 \pm 0.95 *$ \\
\hline $\begin{array}{l}\text { NIH-LH-S3 } \\
\text { plus NIH-FSH-S2 }\end{array}$ & $\begin{array}{l}0.2 \\
2.5\end{array}$ & $\left.\begin{array}{l}\mu \mathrm{g} \\
\mu \mathrm{g}\end{array}\right)$ & 11 & $2.43 \pm 0.45 *$ & $16.6 \pm 3.46^{*}$ \\
\hline Saline & & & 7 & $0.24 \pm 0.10$ & $1.8 \pm 0.81$ \\
\hline LTH & 10 & IU & 7 & $1.33 \pm 0.49$ & $8.0 \pm 2.24 *$ \\
\hline $\mathrm{ACTH}$ & 20 & $\mathrm{mU}$ & 8 & $0.19 \pm 0.05$ & $1.4 \pm 0.32$ \\
\hline
\end{tabular}

Rats were hypophysectomized at 1 p.m. in proestrus. Pituitary hormones were injected intravenously at 3 p.m. Ovarian venous blood was collected for 30 mins. starting at 4 p.m.

a) Mean \pm S.E.

* Statistically significant against hypophysectomized control group $(\mathrm{P}<0.05)$.

LTH: Prolactin, Teikoku-zoki

ACTH: U.S.P. corticotropin reference standard.

venous injection with saline at 3 p.m. resulted in a marked decrease of estrogen secretion at 4 p.m., the level of which was as low as $0.3 \mathrm{ng}$ per $\mathrm{m} l$ plasma comparable to the estrogen level of controls. When the pituitary extract obtained from the rats at 11 a.m. in proestrus, when their estrogen secretion was being maximally stimulated, was administered intravenously at 3 p.m. into the rats hypophysectomized at 1 p.m., the estrogen secretion increased at 4 p.m. 11 -fold over the control level either in concentration ( $\mathrm{ng} / \mathrm{ml}$ plasma) or in secretion rate 
Table 3. Ovarian estrogen secretion after intravenous injection of gonadotropin into rats hypophysectomized at proestrus

3705

\begin{tabular}{|c|c|c|c|c|c|}
\hline Gonad & ropins & $\begin{array}{l}\text { Time after } \\
\text { injection }\end{array}$ & No. of & Ovaria & blood \\
\hline - & & 0 & 8 & $0.33 \pm 0.08^{a)}$ & $2.3 \pm 0.62^{\mathrm{a})}$ \\
\hline NIH-FSH-S 1 & $50 \mu \mathrm{g}$ & 0.5 & 8 & $0.93 \pm 0.26 *$ & $6.7 \pm 1.92 *$ \\
\hline & & 1.0 & 8 & $1.70 \pm 0.56^{*}$ & $13.8 \pm 4.88^{*}$ \\
\hline & & 2.0 & 9 & $3.11 \pm 0.79 *$ & $23.4 \pm 6.94 *$ \\
\hline & & 4.0 & 8 & $0.82 \pm 0.15 *$ & $6.9 \pm 1.93 *$ \\
\hline NIH-LH-S 3 & $50 \mu \mathrm{g}$ & 0.5 & 7 & $1.07 \pm 0.24 *$ & $7.2 \pm 1.34 *$ \\
\hline & & 1.0 & 8 & $2.80 \pm 0.71 *$ & $18.9 \pm 3.85 *$ \\
\hline & & 2.0 & 8 & $1.94 \pm 0.59 *$ & $11.6 \pm 3.22 *$ \\
\hline & & 4.0 & 8 & $0.76 \pm 0.13 *$ & $4.7 \pm 0.64 *$ \\
\hline
\end{tabular}

Rats were hypophysectomized at 1 p.m. in proestrus. Gonadotropins were injected into tail veins 2 hrs. after surgery. Ovarian venous blood was collected for 30 mins. at specified times after gonadotropin injection.

a) Mean \pm S.E., estradiol equivalent

* Statistically significant against $0 \mathrm{hr}$. control $(\mathrm{P}<0.05)$

(ng/hr/ovary). The pituitary extract of 9 p.m. proestrus, when estrogen secretion was turning to decrease, also caused a significant increase of estrogen secretion, the extent of which, however, was significantly less than that produced by the 11 a.m. extract.

The acute effects of various pituitary hormones on the ovarian estrogen secretion were examined under the same experimental conditions, and the results are summerized in Table 2. It is evident that a small amount of $\mathrm{LH}, 0.25 \mu \mathrm{g}$ per rat, caused a statistically significant increase in ovarian estrogen secretion in an hour. The estrogen secretion increased according to the increment of LH dosage, and a massive dose was reeded to recover the secretion to the intact level of proestrus. Under the same conditions, $2.5 \mu \mathrm{g}$ of FSH produced a significant increase in estrogen secretion, but the responses were not dose-dependent up to $250 \mu \mathrm{g}$, even though this amount was not sufficient to restore the estrogen secretion to the intact level of proestrus. Combined usage of $2.5 \mu \mathrm{g} \mathrm{FSH}$ and $0.25 \mu \mathrm{g} \mathrm{LH}$, either part of which could not fully stimulate the estrogen secretion, produced a remarkable increase in ovarian estrogen secretion nearly to the level seen in the intact rat at the equivalent time. LTH (Prolactin, Teikoku-zoki), 10 IU per rat, caused a slight increase of the secretion rate. Based on a parameter of estrogen concentration, however, this increase is not significant. $\mathrm{ACTH}, 20 \mathrm{mU}$ per rat was quite negative in this $1 \mathrm{hr}$. test.

\section{Secretion pattern of estrogen after injec- tion of gonadotropin}

The secreting patterns of estrogen after an intravenous injection of gonadotropins were compared in the rats hypophysectomized at 1 p.m. in proestrus (Table 3). The estrogen secretion began to rise within 30 mins. after the injection of $50 \mu \mathrm{g}$ of NIH-LH-S 3 or NIH-FSH$\mathrm{S}_{1}$, and the time needed to reach the peak was only $1 \mathrm{hr}$. for $\mathrm{LH}$ and $2 \mathrm{hrs}$. for FSH. The peak value in the FSH-treated group appeared to be somewhat greater than that in the LH-treated group either in concentration $(\mathrm{ng} / \mathrm{ml}$ plasma) or in secretion rate $(\mathrm{ng} / \mathrm{hr} /$ ovary). After showing the peak, the estrogen secretion returned toward the level of the hypophysectomized control, but it was still significantly high even 
Table 4. Lack of estrogen secreting activity in the intact ras ovary after completion of ovulatory surge of $\mathrm{LH}$

\begin{tabular}{|c|c|c|c|}
\hline \multirow{2}{*}{ Treatment } & \multirow{2}{*}{$\begin{array}{l}\text { No. of } \\
\text { rats }\end{array}$} & \multicolumn{2}{|c|}{ Ovarian venous blood estrogen } \\
\hline & & $\mathrm{ng} / \mathrm{ml}$ plasma & ng/hr/ovary \\
\hline Saline & 6 & $0.54 \pm 0.32^{a)}$ & $3.3 \pm 2.27^{\mathrm{a})}$ \\
\hline Pituitary extract $\mathrm{I}^{\mathrm{b}}$ ) & 11 & $0.50 \pm 0.24$ & $4.1 \pm 2.20$ \\
\hline
\end{tabular}

Rats were injected intravenously with $0.5 \mathrm{ml}$ of saline or with pituitary extract ( 1 gland equivalent) at 9 p.m. in proestrus. Ovarian venous blood was collected for 30 mins. starting from 10 p.m.

a) Mean \pm S.E., estradiol equivalent

b) Obtained from the proestrous rat at 11 a.m.

Table 5. LH-causing termination of estrogen secretion from the intact rat ovary at proestrus

\begin{tabular}{cccc}
\hline $\begin{array}{c}\text { Time after LH } \\
\text { injection (hrs.) }\end{array}$ & $\begin{array}{c}\text { No. of } \\
\text { rats }\end{array}$ & ng/ml plasma & $\mathrm{ng} / \mathrm{hr} / \mathrm{ovary}$ \\
\hline 0 & 10 & $4.51 \pm 0.92^{\mathrm{a})}$ & $\left.21.3 \pm 5.67^{\mathrm{a}}\right)$ \\
3 & 8 & $3.17 \pm 0.78$ & $18.3 \pm 4.67$ \\
4.5 & 8 & $0.51 \pm 0.06$ & $3.2 \pm 0.28$ \\
6 & 9 & n.d. & - \\
Saline control & 8 & $3.00 \pm 0.31$ & $18.9 \pm 2.90$ \\
6 & & & \\
\hline
\end{tabular}

Gonadotropin (NIH-LH-S $250 \mu \mathrm{g}$ ) was injected into the tail vein of intact rats at 11 a.m. of proestrus with a volume of $0.5 \mathrm{ml}$.

a) Mean \pm S.E., estradiol equivalent

4 hrs. after hormone administration. This suggests that there is no significant difference between LH and FSH in their integrated effects on estrogen secretion, although FSH looks like more potent than LH when the responses are compared 2 hrs. after injection.

Delayed effect of gonadotropin on ovarian estrogen secretion in proestrus

A rapid fall of elevated estrogen secretion during the time of LH release (Miyake, 1968; Hori et al., 1968; Kobayashi et al., 1968) may suggest a possibility of LH terminating preovulatory estrogen secretion. The following experiments were conducted, therefore, to substantiate this concept. As shown in Table 4, estrogen concentration in ovarian venous blood at $10 \mathrm{p} . \mathrm{m}$. of proestrus was as low as $0.54 \mathrm{ng} / \mathrm{ml}$ plasma, which was almost similar to the value $(0.66 \mathrm{ng} / \mathrm{ml}$ plasma) determined at 9 p.m. of proestrus (Hori et al., 1968). The intravenous injection of pituitary extract at 9 p.m. hardly produced any stimulation to the estrogen secretion at 10 p.m., whereas the same extract showed a marked stimulation when administered at 3 p.m. into the rats hypophysectomized at 1 p.m. of proestrus as depicted in Table 1 . This suggests that a sudden decrease of estrogen secretion in the pre-ovulatory phase is caused by the lack of reactivity of ovarian tissue to the pituitary factor, and not by the lack of a pituitary factor in stimulating estrogen secretion.

Subsequently, a large dose of $\mathrm{LH}, 250 \mu \mathrm{g}$ per rat, was injected into the intact rats at 11 a.m. in proestrus to clarify whether exogenous LH terminated the fully stimulated estrogen secretion in proestrus. This may correspond to a 6-hrs. advancement of normal ovulatory surge of $\mathrm{LH}$ in our rats. The results are presented in Table 5 showing that no significant change of 
Table 6. Gonadotropin-causing termination of estrogen secretion from the intact rat ovary at proestrus

\begin{tabular}{lcccc}
\hline \hline \multicolumn{2}{c}{ Treatment } & $\begin{array}{c}\text { No. of } \\
\text { rats }\end{array}$ & \multicolumn{2}{c}{ Ovarian venous blood estrogen } \\
\end{tabular}

Gonadotropins were injected into the tail vein of intact rats at 11 a.m. of proestrus with a volume of $0.5 \mathrm{~m} l$ saline. Ovarian venous blood was collected for 30 mins. starting at 5 p.m.

a) Mean \pm S.E., estradiol equivalent

b) The data are transferred from Table 5 .

* Statistically significant against hypophysectomized control group at $\mathrm{P}<0.05$.

the estrogen secretion is made $3 \mathrm{hrs}$. after injection and that a decrease to an undetectable level at $6 \mathrm{hrs}$. after injection ensues. The controls still kept a high level of $3.0 \mathrm{ng}$ per $\mathrm{m} l$ plasma even $6 \mathrm{hrs}$. after saline injection. It is evident, therefore, that exogenous LH has no additional stimulating effect on ovarian estrogen secretion which has been fully stimulated by endogenous stimulating factor(s), but it terminates the highly elevated estrogen secretion within $6 \mathrm{hrs}$. from the ovary having ripened follicles. This means that the termination of estrogen secretion which normally occurs between 7 and 9 p.m. is hastened by about 6 hrs. when LH is administered $6 \mathrm{hrs}$. prior to the critical time of LH release.

Varying doses of LH and FSH were injected into the intact rats at 11 a.m. of proestrus in order to compare their terminating effects on ovarian estrogen secretion (Table 6). A drop in ovarian venous estrogen level at 5 p.m. to a minimal level was induced by giving $\mathrm{LH}$ or FSH at 11 a.m. at a minute dose as small as $10 \mu \mathrm{g}$ per rat. This suggests that a normal release of ovulating hormone (probably LH plus FSH) may be enough to terminate a highly elevated secretion of estrogen at the preovulatory stage.

\section{Discussion}

The present results together with the previous ones (Hori et al., 1968) confirm the hypophyseal dependency of estrogen secretion from the rat ovary having ripened follicles. The proestrous estrogen secretion is minimized immediately after hypophysectomy and is restored within 1 to $2 \mathrm{hrs}$. by the intravenous injection of rat pituitary extract or by giving gonadotropin preparations. Therefore, it may be suggested that estrogen synthesis in the rat ovary having ripened follicles is directly stimulated by pituitary hormones, the process of which is not mediated through proliferation of estrogen forming cells during follicle growth. In this connection, no clear-cut acute effect of exogenous gonadotropin on the secretion rate of estrogen into the ovarian venous blood was demonstrated in the mare (Short, 1964) as well as in the sheep (Domański et al., 1967). In these experiments, a possibility remained that the ovary had fully been stimulated by the endogenous pituitary factor(s) in promoting estrogen secretion.

The comparison of the amounts of estrogen secreted in $4 \mathrm{hrs}$. after administration of an ovine FSH preparation (NIH-FSH-S 1 ) and an 
ovine LH preparation (NIH-LH-S 3 ) leads us to believe that both preparations had almost the same acute effect on promoting estrogen secretion, although NIH-LH-S1 seemed to act faster than NIH-FSH-S3 and the effect of the latter seems to be somewhat longer-lasting than that of the former. The increase in estrogen secretion caused by exogenous gonadotropin does not prove what is an actual endogenous factor stimulating estrogen secretion. There are a number of reports demonstrating that the plasma LH level before ovulatory release of LH does not exceed $0.1 \mu \mathrm{g}$ per $\mathrm{ml}$ of plasma (Ramirez and McCann, 1964; Anderson and McShan, 1966; Schwartz and Caldarelli, 1965). The recent experiments made by Kobayashi et al., (1968) in our laboratory, using the rats bred under the same conditions as described previously, have demonstrated that $\mathrm{LH}$ in peripheral blood is not detected through the diestrous stage and in the proestrous morning and early afternoon before 5 p.m., during the period of which a tremendous increase in ovarian estrogen secretion takes place (Hori et al., 1968). In contrast with LH, plasma FSH in the proestrous morning appears to be as high as $80 \mu \mathrm{g}$ per $\mathrm{m} l$ (Igarashi, 1967) or $2.5 \mu \mathrm{g}$ per $\mathrm{ml}$ (McClintock and Schwartz, 1968). If these data were correct, the circulating amount of FSH during the time before LH release would be enough to produce a full stimulation of estrogen secretion, since a minute dose of NIH-FSH-S ${ }_{1}$, as small as $2.5 \mu \mathrm{g}$, is capable of stimulating estrogen secretion in the rat hypophysectomized at proestrus (Table 2). The possibility still remains that a small amount of LH tonically secreted through the cycle cooperates with FSH directly in stimulating estrogen secretion.

In our rats, $\mathrm{LH}$ release starting at 5 p.m. in proestrus (Kobayashi et al., 1968) almost synchronizes with a prompt increase in progesterone secretion (Uchida et al., 1969a) and a sudden drop of estrogen secretion occurs between 7 and 9 p.m. in proestrus (Hori et al., 1968). This suggests that ovulatory surge of LH terminates estrogen secretion and agrees with an earlier assumption of Schwartz (1964) who mentioned that the ovulatory surge of LH decreases estrogen secretion to a minimal level since uterine weight falls between proestrus and estrus regardless of the presence of the ovaries. The present experiments demonstrated that either LH or FSH administered intravenously with a small dose as small as $10 \mu \mathrm{g}$ per rat terminates the estrogen secretion in preovulatory rats. The estrogen secretion is terminated by $\mathrm{LH}$ with a time lag of $3 \mathrm{hrs}$. or more, which is equivalent to the time interval between the release of ovulating hormone and the start of fall in estrogen secretion in normal cyclic rats. This termination of estrogen, therefore, may be considered as a delayed and indirect action of gonadotropins on the estrogen forming cells. It should be noted that the dose of FSH required for this effect is not only equivalent to that of $\mathrm{LH}$ but also equivalent to the dose need for inducing ovulation in the rats having mature follicles in their ovaries. Lostroh and Johnson (1966) indicated that the dosage of either FSH or LH, as small as $20 \mu \mathrm{g}$, was able to induce ovulation in the gonadotropin treated rat. Furthermore, there are evidences to show that FSH is also released from the pituitary (Gans et al., 1964; Caligaris et al., 1967; Goldman and Mahesh, 1968; McClintock and Schwartz, 1968) at the time, so-called "critical period", for LH release (Everett et al., 1949). Goldman and Mahesh (1968) also demonstrated that only $15 \mu \mathrm{g}$ of FSH is capable of inducing ovulation in the PMS-treated immature rat, and the amount of FSH required for ovulation in the rat having mature follicles is almost equivalent to the amount of pituitary FSH decreased in the afternoon of proestrus. The amount of gonadotropins released in the ovulatory surge is estimated at about $15 \mu \mathrm{g}$ for LH (Schwartz and Gold, 1967) and $8 \mu \mathrm{g}$ for FSH (McClintock and Schwartz, 1968). Although a possible role of FSH surge during the process of ovulation is not clear yet, but it is likely that the termination of estrogen secretion caused by ovulating hormone (probably LH plus FSH) is an inevitable phenomenon preceding ovulation. It 
is considered, therefore, that a sufficient amount of gonadotropins, either given exogenously or released endogenously from the pituitary, act upon the ripened follicles of the proestrous ovary which has been fully developed by basal secretion of gonadotropins and that the follicular elements differentiate towards ovulation, in the process of which the estrogen forming cells lose their ability to secrete estrogen even under the exposure of a powerful stimulating factor.

It is not likely that progesterone secreted with a rapid increase during the release of LH is causative of the termination of estrogen, since $10 \mu \mathrm{g}$ of FSH which is able to terminate estrogen secretion is not capable of stimulating progesterone secretion in the proestrous afternoon (Uchida et al., 1969b). A possibility was pointed out by Goldman and Mahesh (1968) that FSH might induce ovulation without causing a preovulatory increase in progesterone secretion. These facts lead us to speculate that the site of action of gonadotropins on steroid synthesis in ovarian tissue at the preovulatory stage is not common to both estrogen and progestin, and each of those steroids may be separately produced in the different follicular elements under the control of gonadotropins.

In this connection, Short $(1962,1964)$ proposed a "two-cell type" theory of steroid synthesis in the equine ovary, in which he suggested that preovulatory follicles in the mare mainly secrete estrogen from the theca interna cells, since they are equipped with all the enzymes required for producing aromatic steroids, whereas the follicles ruptured at the time of ovulation, the granulosa cells suddenly came to be exposed in the circulating blood and immediately gained ability to produce mainly progesterone, because they are not equipped with either 17-hydroxylase or 17-desmolase. In this conception, the cyclical changes in estrogen and progesterone secretion are explained as a direct consequence of cellular changes in the ovary which are controlled indirectly by the changes of pituitary gonadotropic activity. Such an explanation for a quick change of the secretion pattern of ovarian steroids can not be applied as it is for the rat, since the preovulatory secretions of both ovarian steroids are acutely depended upon the pituitary (Hori et al., 1968; Uchida et al., 1969a), and progesterone secretion elevates approximately $12 \mathrm{hrs}$. prior to ovulation and turns to decrease at the time of ovulation.

The mechanism by which ovulating hormone causes termination of estrogen secretion has not been clear, but it may be speculated that the ovulating hormone causes the development and differentiation of the follicle in such a rapid way that the theca cells may be separated from granulosa cells, when cooperation of these two types of cells may eventually be required for estrogen secretion (Flack, 1959; Short, 1964). In regard to this, it is interesting to note that LH in vitro inhibited the conversion of androgen to estrogen in the ovarian slice obtainéd from the rat in proestrus and metoestrus (Chatterton et al., 1969). Similar effect of FSH on the bovine follicle was reported by Oakey and Stitch (1968).

The outcome of our experiments has an important implication as to how ovarian estrogen secretion is regulated. A relatively small amount of exogenous gonadotropin comparing with the circulating amount of endogenous one is capable of terminating estrogen secretion from the proestrous ovary, whose secreting function has been fully stimulated by endogenous gonadotropins. The ovulating hormone, a pituitary factor to stimulate estrogen secretion, is released when estrogen secretion is maximally stimulated. These facts suggest that the secreted estrogen does not acutely feedback to suppress its further secretion. In addition, the estrogen dependency of pituitary LH release in the cyclic rat has been firmly established by numerous evidences (Everett, 1944; 1947, 1948; Greep and Jones, 1950; Sawyer, 1964; Schwartz, 1964; Palka et al., 1966; Kobayashi et al., 1969), but the released LH can not stimulate further estrogen secretion, as described here. Therefore, it may be assumed that neither positive nor negative feedback 
loop acutely operates between the estrogen secreting system and the gonadotropin secreting system in the preovulatory rat. This does not imply, however, that there is no feedback control mechanism for the secretion of both estrogen and gonadotropins during the estrous cycle in the rat. Assuming such a feedback system, it must include many non-linear factors, for example, follicular growth, differentiation of follicles towards ovulation followed by luteinization, and neural mechanisms for the release of gonadotropins. Therefore, such a complicated self-regulatory mechanism should be distinguished from a concept which involves a simple feedback control mechanism.

\section{Acknowledgments}

The authors gratefully acknowledge the technical assistance of $\mathrm{Mr}$. Goro Kato through the completion of this work. The authors are indebted to the Endocrinology Study Section, National Institutes of Health, U.S.A. for generous supply of NIH-LH-S , NIH-LH-S 12 , NIH-FSH-S 1 and NIH-FSH-S4.

\section{References}

Anderson, R. R. and W. H. McShan (1966). Endocrinology 78, 976.

Barnea, A., T. Gershonowitz and M. C. Shelesnyak (1968). J. Endocrinol. 41, 281.

Caligaris, L., J. J. Astrada and S. Taleisnik (1967). Endocrinology 81, 1261.

Chatterton, R. T., A. J. Chatterton and R. O. Greep (1969). Ibid. 84, 252.

Domański, E. L., Skrzeczkowski, E. Stupnicka, R. Fitko and W. Dobrowolski (1967). J. Reprod. Fert. 14, 365.

Everett, J. W. (1944). Endocrinology 34, 136.

Everett, J. W. (1947). Ibid. 41, 364.

Everett, J. W. (1948). Ibid. 43, 389.

Everett, J. W., C. H. Sawyer and J. E. Markee (1949). Ibid. 44, 234.

Fevold, H. L. (1941). Ibid. 28, 33.

Flack, B. (1959). Acta physiol. Scand. Suppl. 163.
Gans, E., S. E. de Jongh, G. P. van Rees, J. J. van der Werff ten Bosch and O. L. Wolthuis (1964). Acta Endocrinol. 45, 335.

Goldman, B. D. and V. B. Mahesh (1968). Endocrinology 83, 97.

Greep, R. O., H. B. Van Dyke and B. F. Chow (1942). Ibid. 30, 635.

Greep, R. O. and I. C. Jones (1950). Recent progr. Hormone Res. 5, 197.

Hori, T., M. Ide and T. Miyake (1968). Endocrinol. Japon. 15, 215.

Igarashi, M. (1967). 19th Annual Meeting of the Japanese Obstetrical and Gynecological Society (lecture)

Kobayashi, F., K. Hara and T. Miyake (1968). Endocrinol. Japon. 15, 313.

Kobayashi, F., K. Hara and T. Miyake (1969). Ibid. 16, 261.

Lostroh, A. J. and R. E. Johnson (1966). Endocrinology 79, 991.

McClintock, J. A. and N. B. Schwartz (1968). Ibid. 83, 433.

Miyake, T. (1968). Integrative Mechanism of Neuroendocrine system, Hokkaido University Medical Library Series, vol. 1. p. 139.

Oakey, R. E. and S. R. Stich (1968). Acta Endocrinol. 58, 407.

Palka, Y. S., V. D. Ramirez and C. H. Sawyer (1966). Endocrinology 79, 907.

Ramirez, V. D. and S. M. McCann (1964). Ibid. 74, 814.

Sawyer, C. H. "Gonadotropins" Cole, H. H. (ed). Freeman, San Francisco and London, p. 113 (1964).

Schwartz, N. B. (1964). Am. J. Physiol. 207, 1251.

Schwartz, N. B. and Caldarelli (1965). Proc. Soc. Exptl. Biol. Med. 119, 16.

Schwartz, N. B. and J. J. Gold (1967). Anat. Rec. 157, 137.

Short, R. V. (1962). J. Endocrinol. 24, 59.

Short, R. V. (1964). Recent Progr. Hormone Res. 20, 303.

Tanaka, A. (1955). Annual Report of Shionogi Res. Lab. 5, 678.

Uchida, K., M. Kadowaki and T. Miyake (1969a). Endocrinol. Japon. 16, 227. 
Uchida, K., M. Kadowaki and T. Miyake (1969b). Ibid. 16, 239. 